\title{
Abstract \\ Neurological Development and Serum Lipids and Lipoproteins in a Coronary Heart Disease Prevention Trial in Childhood. The STRIP Project
}

\author{
LEENA RASK-NISSILÄ, M.D., M.Sc. \\ The winner of the Väinö Kannisto Fund Award in 2002
}

The Department of Pediatrics, the Department of Medicine and the Research Center of Applied and Preventive Cardiovascular Medicine, University of Turku, and the Research and Development Center of the Social Insurance Institution, Turku, Finland. Annales of Universitatis Turkuensis, University of Turku, Turku, Finland 2002.

In the prospective randomized STRIP project, a low-saturated fat, low-cholesterol diet was introduced to the intervention families of 7 -month-old infants $(\mathrm{n}=540)$. Control infants $(\mathrm{n}=522)$ consumed an unrestricted diet. Nutrient intakes, serum lipid values and growth were studied frequently. Five-year-old children $(n=496)$ participated in the neurodevelopmental tests.

The fat, saturated fat and cholesterol intakes of the intervention children were continuously less than those of the control children. The neurological development of 5year-old intervention children was at least as good as that of the control children. Total fat and saturated fat intakes, serum cholesterol concentrations and apolipoprotein (apo) E phenotype did not associate with the children's neurodevelopment. In boys, high intakes of protein, polyunsaturated fatty acids and cholesterol predicted a favorable outcome in the neurodevelopmental tests. Serum cholesterol concentrations were continuously $3-5 \%$ lower in the intervention children than in the control children. Five-year-old intervention boys had $9 \%$ lower mean serum LDL cholesterol concentrations than the control boys, whereas no difference was seen in girls. Serum triglyceride concentrations were similar in the two groups. Dietary intervention did not influence the tracking of serum lipids and lipoproteins, which remained strong during the follow-up. The tracking of non-HDL cholesterol and apoB in children with apoE phenotypes $2 / 3$ or $3 / 3$ was stronger than that in the other children, and the tracking of HDL cholesterol was stronger in the boys than in the girls.

The results of the STRIP study show that saturated fat and cholesterol restrictions due to repeated, individualized dietary counseling during the first 5 years of a child's life reduce age-associated increases in children's serum cholesterol concentrations without any adverse impact on their neurological development.

Keywords: diet, nutrition, fat, cholesterol, children, child development, apolipoprotein E, tracking, coronary heart disease risk factors, atherosclerosis prevention 
